\title{
Hepatitis B and Hepatitis C Virus Infection among End Stage Renal Disease Patients on Maintenance Hemodialysis, Their Family Members and Dialysis Staffs - A Prevalence Study
}

\author{
Hossain $\mathrm{RM}^{\mathrm{a}}$, Iqbal MM ${ }^{\mathrm{b}}$, Rahman $\mathrm{ZF}^{\mathrm{c}}$, Sultana $\mathrm{R}^{\mathrm{d}}$, Rahman $\mathrm{MH}^{\mathrm{e}}$, Islam $\mathrm{MN}^{\mathrm{f}}$, Khan $\mathrm{NN}^{\mathrm{g}}$, \\ Mansur MA ${ }^{\mathrm{h}}$, Rahman MA ${ }^{\mathrm{i}}$, Iqbal Si, Hassan $\mathrm{MS}^{\mathrm{k}}$
}

\begin{abstract}
Background: Hepatitis $B(H B V)$ and hepatitis $C$ virus (HCV) infection is common among patients on maintenance hemodialysis (MHD). This study was undertaken to observe prevalence of hepatitis $B$ and $C$ infection in hemodialysis patients, their family members and dialysis staffs.

Methods: In this cross-sectional study 3 groups were included as gr-1 patients on MHD, the first-degree relatives in gr-2 and the dialysis staffs as gr-3. Clinical and laboratory investigations were done. Viral serology included hepatitis B surface antigen (HBsAg) and antibody against hepatitis $C$ virus (anti-HCV) done by enzyme linked immunosorbent sorbent assay (ELISA) method.

Results: Total 150 subjects were analyzed where 50 were in gr-1, $60 \mathrm{gr}-2$ and 40 in gr-3. In gr-1 MHD patients, $\mathrm{HBV}$ infection was positive in $12 \%$ and $\mathrm{HCV}$ in $71 \%$. None of the viral markers were positive in family members and dialysis staffs. Blood transfusion (BT) was taken by $76 \%$ MHD patents. The frequency of $H B V$ and $H C V$ infection was of similar pattern in both BT dependent and non BT group $(P=N S)$. When HCV positive and negative patents were (71 vs. 29\%, p<0.001) compared, dialysis duration (37 \pm 34 vs. $11 \pm 6$ months, $p<0.001)$ was found higher in positive patients.

Conclusion: This survey on dialysis patients showed that prevalence of hepatitis $B$ and $C$ virus infections was higher in Bangladeshi patients on MHD groups. Horizontal spread of these viruses is negligible in caregivers and dialysis staffs.
\end{abstract}

Key words: Hepatitis B virus, Hepataitis C Virus, Infection, first degree relative, hospital staff.

(BIRDEM Med J 2018; 8(1): 42-46)

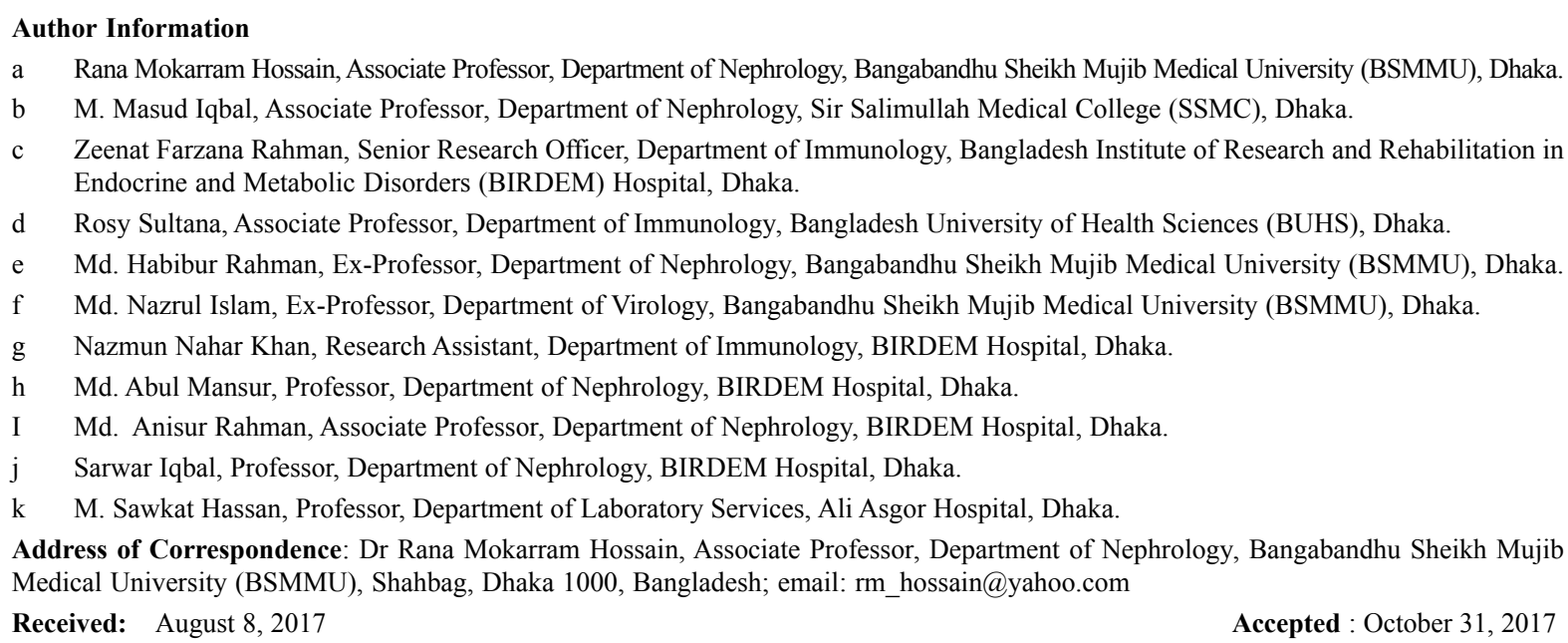




\section{Introduction}

Dialysis is a mode of renal replacement therapy, which is required by the end stage renal disease (ESRD) patients for survival. It can either be in the form of hemodialysis (HD) or peritoneal dialysis (PD). Most of the ESRD patients depend on HD all over the world. A study showed that around $80-85 \%$ patients are on HD in Bangladesh. ${ }^{1}$ There are different complications in this modality and out come of hemodialysis depends largely on the management of these complications. Most important ones are dialysis adequacy, infections (viral, bacterial), malnutrition, cardiovascular (hypertension, heart failure, stroke) and these are responsible for majority of the morbidity and mortality in HD patients. 2,3 Hepatitis is of interest in the renal community and patients with ESRD may have acute or chronic hepatitis. The acute forms of viral hepatitis is commonly due to hepatitis A, hepatitis B and hepatitis E. Patients on dialysis suffer frequently from chronic hepatitis with increased frequency of hepatitis B (HBV) and C (HCV), the incidence of which increases with duration of dialysis. ${ }^{4,5}$

Dialysis patients may acquire hepatitis virus infection in several ways, including internally contaminated dialysis equipment that are not routinely changed after each use; injections and breaks in the skin or mucous membranes when in contact with blood-contaminated objects. Various routes of B and C transmission can occur in hemodialysis units. Also these patients are immune compromised. ${ }^{6}$ Staff members may become infected with HBV / HCV through accidental needle punctures or breaks in their skin or mucous membranes, since they may have frequent and regular contact with blood and blood-contaminated surfaces.

Not many properly designed scientific studies have been undertaken in Bangladesh in dialysis population to identify prevalence of hepatitis $\mathrm{B}$ and $\mathrm{C}$ infection. Similarly no proper investigation is carried out regarding horizontal spread of the disease in family members and risk prone dialysis staffs, which includes doctors, nurses and laboratory personnel. This study was undertaken to observe prevalence of hepatitis $\mathrm{B}$ and $\mathrm{C}$ infection in hemodialysis patients, their family members and dialysis staffs.

\section{Methods}

This cross-sectional study was carried out in the Departments of Nephrology, Bangabandhu Sheikh Mujib Medical University (BSMMU) and Bangladesh Institute of Research and Rehabilitation in Diabetes, Endocrine and Metabolic Disorders (BIRDEM) Hospital, Dhaka from 2004-5. Patients with ESRD on maintenance dialysis as gr-1, the first-degree relatives (parents, spouse and offspring) of the selected patients as gr-2 and the dialysis staffs (doctors, nurses, dialysis technicians) as gr-3 from the respective centers were included.

History regarding past and present illness, examination with special emphasis to hepato-billiary system was done. Anthropometric evaluation for height, weight and BMI was measured. Blood sampling was done by taking blood immediately before starting of a session. Laboratory investigations included serum creatinine, fasting sugar, total protein, albumin, bilirubin, alanine amino transferase and alkaline phosphatase. Viral serology included hepatitis B surface antigen (HBsAg), antibody against hepatitis B surface antigen (anti$\mathrm{HbsAg}$ ) and antibody against hepatitis $\mathrm{C}$ virus (anti$\mathrm{HCV}$ ) done in all patients by enzyme linked immunosorbent assay (ELISA) method.

\section{Results}

Among 150 study subjects 50 was in gr- 1 from MHD patients, 60 family members as gr- 2 and 40 dialysis staffs as gr-3 were included.

Age of the 3 groups was $48 \pm 13,33 \pm 12$ and $36 \pm 9$ years $(p<0.001)$ respectively being gr $2 \& 3$ younger than MHD patients and body mass index (BMI) was $22 \pm 3$, $25 \pm 42$ and $24 \pm 4 \mathrm{~kg} / \mathrm{m}^{2}(\mathrm{p}<0.02)$ showing a lower BMI in HD patients. The serum creatinine was $9.1 \pm 2.4$, $0.9 \pm 0.1$ and $0.80 .2 \mathrm{mg} / \mathrm{dl}(\mathrm{p}<0.001)$ in 3 groups with higher value in dialysis patients. Percentage of nondiabetic and diabetic dialysis patients was $59 \%$ versus $41 \%(\mathrm{P}=\mathrm{NS})$. Non-diabetic diseases included glomerulonephritis, hypertension, polycystic kidney disease (PKD), obstructive uropathies, etc. The family members and dialysis staffs had no known renal disease and their serum creatinine was within normal range.

Group $1 \mathrm{HBV}$ infection was positive in $12 \%$ and $\mathrm{HCV}$ in $71 \%$. None of the viral markers were positive in family members and dialysis staffs (table-1). Vaccination against $\mathrm{HBV}$ was done in $75 \%$ patients of gr- 1 . 
Table I. HBV and HCV Status in study subjects

\begin{tabular}{lcccc}
\hline & \multicolumn{2}{c}{ HBsAg } & \multicolumn{2}{c}{ Anti-HCV } \\
\hline Subjects & $+\mathrm{ve}$ & $-\mathrm{ve}$ & $+\mathrm{ve}$ & -ve \\
Groups & $(\mathrm{n}) \%$ & $(\mathrm{n}) \%$ & $(\mathrm{n}) \%$ & $(\mathrm{n}) \%$ \\
\hline Gr-1MHD & $(6) 12$ & $(44) 88$ & $(36) 71$ & $(14) 29$ \\
Gr-2Family member & 0 & 100 & 0 & 100 \\
Gr-3Dialysis staff & 0 & 100 & 0 & 100 \\
\hline
\end{tabular}

Blood transfusion (BT) was taken by $76 \%$ MHD patents during dialysis with a mean $1.4 \pm 0.8$ units/month (0.33). These BT dependent MHD patients showed that 13\% were positive for $\mathrm{HBV}$ and $87 \%$ for $\mathrm{HCV}$ infection. The rest 24\% MHD patients, those who did not take any $\mathrm{BT}$, were $12 \%$ and $88 \%$ positive for $\mathrm{HBV}$ and $\mathrm{HCV}$ respectively. The frequency of $\mathrm{HBV}$ and $\mathrm{HCV}$ infection was of similar pattern in both BT dependent and non BT group $(\mathrm{P}=\mathrm{NS})$.

When HCV positive and negative patents were (71 vs. $29 \%, \mathrm{p}<0.001)$ compared, dialysis duration $(37 \pm 34$ vs. $11 \pm 6$ months, $p<0.001$ ) was found higher in positive patients. BT during dialysis was similar in both groups as $1.2 \pm 0.7$ vs. $1.6 \pm 0.7$ units/month $(\mathrm{P}=\mathrm{NS})$. The liver function tests (LFT) were also similar in 2 groups (ALT$26 \pm 9$ vs. $23 \pm 9 \mathrm{U} / 1$, Bilirubin $0.3 \pm 0.1$ vs. $0.2 \pm 0.1$ $\mathrm{mg} / \mathrm{l}$ and Alkaline Phosphatase $262 \pm 138$ vs.230 \pm $149 \mathrm{U} / 1, \mathrm{P}=\mathrm{NS}$ ). This indicates that longer duration of $\mathrm{HD}$ is a risk factor for $\mathrm{HCV}$ infection. When HBV positive and negative ( 12 vs. $88 \%, \mathrm{p}<0.001)$ patients were compared, duration of dialysis this time was similar in both groups, BT was $1.4 \pm 1.7$ vs. $1.3 \pm 0.7$ units/month $(\mathrm{P}=\mathrm{NS}$ ) and again LFT was normal (ALT- $25 \pm 4$ vs. 25 $\pm 9 \mathrm{U} / \mathrm{l}$, Bilirubin $0.2 \pm 0.1$ vs. $0.3 \pm 0.1 \mathrm{mg} / \mathrm{l}$ and Alkaline Phosphatase $286 \pm 181$ vs. $247 \pm 137$ U/l, P = NS) and similar in both.

When non-diabetic and diabetic ( 59 vs. $41 \%, \mathrm{P}=\mathrm{NS}$ ) dialysis patients were compared for HBV infectivity, it was similarly positive in both groups $(12 \%$ vs. $12 \%$, $\mathrm{P}=\mathrm{NS}$ ). For HCV infectivity it was $80 \%$ vs. $59 \%$ ( $\mathrm{p}<$ 0.05 ) showing a higher prevalence of $\mathrm{C}$ infection in nondiabetics. The duration of dialysis was also higher in non-diabetics than diabetics ( $40 \pm 36$ vs. $14 \pm 2$ month, $\mathrm{p}<.002)$. In both groups renal function, BT $(1.6 \pm 0.8 \mathrm{vs.}$ $1.1 \pm 0.7$ units/month, $\mathrm{P}=\mathrm{NS})$ and LFT were similar.
Table II. Liver function tests in all 3 groups

\begin{tabular}{lccc}
\hline Parameters & Groups & Mean \pm SD & Significance \\
\hline STP (g/dl) & 1 & $7.4 \pm 1.0$ & NS \\
& 2 & $8.1 \pm 0.5$ & \\
ALB (g/dl) & 3 & $7.7 \pm 0.9$ & \\
& 1 & $3.6 \pm 0.5^{*}$ & 0.001 \\
& 2 & $4.5 \pm 1.3$ & \\
SGPT (U/l) & 3 & $4.1 \pm .03$ & \\
& 1 & $25 \pm 18^{*}$ & 0.001 \\
& 2 & $16 \pm 9$ & \\
Ferritin (ng/dl) & 1 & $327^{*}$ & 0.006 \\
& 2 & 75 & \\
& 3 & 78 & \\
CRP (mg/l) & 1 & $11.7 \pm 10^{*}$ & 0.001 \\
& 2 & $2.5 \pm 1.2$ & \\
& 3 & $2.9 \pm 1.1$ & \\
Bilirubin (mg/dl) & 1 & $0.7 \pm 0.1$ & NS \\
& 2 & $0.2 \pm 0.1$ & \\
& 3 & $0.3 \pm 0.1$ & \\
\hline
\end{tabular}

Note: * indicates significant difference with other groups

\section{Discussion}

Prevalence of HBV infection among dialysis patients at times in developed countries are reported $6.2 \%$ among patients and 5.2\% among staff. Now-a-days, after adopting strict infection control protocols, this has come down to $0.08 \%$ for patients and $0.05 \%$ for staff in hemodialysis units. ${ }^{7}$ In Bangladesh, around 14\% of all patients on MHD were serologically positive for hepatitis B infection shown in a registry report of 198696. ${ }^{1}$ In the present study a similar prevalence of HBV infection in dialysis is seen. Results showed that onefourth HD patients were not vaccinated in this study. HBV infection can be prevented by active immunity. The rate of HBV infection can further be decreased by vaccinating all patients.

Prevalence of HCV among hemodialysis patients in different countries are reported as Netherlands $3 \%$, UK $10.2 \%$, USA $30.0 \%$, Japan $44.0 \%$, Taiwan $60.0 \%$ and Egypt $80.0 \%{ }^{8}$ The infection rate in this study, as evidenced by anti-HCV positivity, is similar to Egypt. ${ }^{8}$ 
BT is one of the risk factors associated with $\mathrm{HCV}$ infection among hemodialysis patients and it is positively related to units of blood transfused and years on dialysis. ${ }^{9}$

Studies also showed that number of years on dialysis is the major risk factor independently associated with higher rates of $\mathrm{HCV}$ infection. The prevalence of $\mathrm{HCV}$ infection increases from $12 \%$ to $37 \%$ after five years on HD. 10

In this study it was also identified that $\mathrm{HCV}$ positivity was more in longer duration dialyzed patients. Although two-thirds of the patients were on BT but that did not have any significant influence on prevalence of the hepatitis viruses.

The registry reports from seven Asia-Pacific countries showed prevalence of HBV during 2001-2005 ranged between $1.3 \%$ and $14.6 \%$. The prevalence of HCV in the same region ranged between $0.7 \%$ and $18.1 \%$. In these countries, frequency of $\mathrm{HCV}$ infection was significantly higher in HD patients than in PD patients. In Australia and New Zealand, the prevalence showed decreasing tendency. ${ }^{11}$ Similar changes in decreasing pattern has yet not occurred in this region of subcontinent primarily because of poor socio-economic status, dependency on BT, dialyzer re-use, improper cleansing, implementing barrier nursing and poor nutritional status. The variability in HBV and HCV prevalence in regions reflects variable clinical practices, such as dialyzer reuse, BT policies or adherence to infection control guidelines for dialysis units.

Dialysis staffs and care givers of HD patients are at risk of virus infectivity. In the presenting study none of the dialysis staffs and relatives of the patients were positive for either of the hepatitis viruses. In a study health-care workers and patient relatives were screened for presence of anti-HCV and they found $2.45 \%$ of the health-care staff and $5.8 \%$ of the relatives were anti-HCV positive subjects. ${ }^{12}$ In another study the investigation of positive cases of HD patients for anti-HCV were extended to their partners and relatives. None of them proved to be positive. ${ }^{13}$ They indicated that the ways of transmission of HCV infection differ in some other ways. All the dialysis staffs of both centers in this study were vaccinated and probably that gave them sero- protection from the $\mathrm{B}$ virus. None of the family members or dialysis staffs was positive for $\mathrm{HCV}$ infection indicating horizontal spread of this virus carries lesser risk.

\section{Conclusions}

This survey on dialysis patients showed that prevalence of hepatitis $\mathrm{B}$ and $\mathrm{C}$ virus infections was higher in our Bangladeshi HD patient groups. Frequency of these two virus infection was similar among those receiving transfusion or not indicating BT alone may not be the regulatory factor for spread of infection. Particularly very high $\mathrm{HCV}$ infection rate is there which may be related to longer duration of dialysis. Horizontal spread of these viruses is negligible in caregivers and dialysis staffs. Until and unless dialysis units adopts strict infection-control procedures designed to prevent transmission of viral pathogens, the patients, their caregivers and service providers will be at increased risk to become infected.

Conflict of interest: Nothing to declare.

Funding: Partially supported by the research grant from Ministry of Science and Technology, Bangladesh.

\section{References}

1 Rashid H U. 1986 - 1996: Bangladesh renal registry report. Bangladesh Renal J 2002; $21: 25$ - 28.

2 Bregman H, Daugirdas JT, Ing TS. Complications during dialysis. In: Hand Book of Dialysis,Little Brown Company, New York, 1995.

3 Daugirdas JT. Dialysis Hypotension:A hemodynamic analysis. Kidney Int1991;39:233-46.

4 Brillanti S, Masci C, Ricci P, Miglioli M, Barbara L. Significance of IgM antibody to hepatitis $\mathrm{C}$ virus patients with chronic hepatitis C. Hepatology 1992;25:998.

5 Sherard DJ et al. The spectrum of bone disease in end stage renal failure-an evolving disorder. Kidney Int 1993;43:436.

6 Hörl W H. Neutrophil function and infections in uremia. Am J Kidney Diseases1999;33: xlv-xlviii.

7 Fabrizi F, Lunghi G, Martin P. Hepatitis B virus infection in hemodialysis: recent discoveries. J Nephrol 2002; 15: 46367.

8 Saxena A K, Panhotra B R. Impact of dedicated space, dialysis equipment, and nursing staff on the transmission of hepatitis $\mathrm{C}$ virus in a hemodialysis unit of the Middle East.Am J Infect Control 2003;31:26-33 
9 Moyer LA, Alter MJ. Hepatitis C virus in the hemodialysis setting: A review with recommendations for control, Semin Dial 1994; 7: 124-27.

10. Chan TM, Lok ASF, Cheng IKP, Chan RT. Prevalence of hepatitis $\mathrm{C}$ virus in hemodialysis patients: A longitudinal study comparing the results of RNA and antibody assays. Hepatology 1994; 17: 5-8.

11 Johnson DW, Dent H, Yao Q, Tranaeus A, Huang CC, Han DS. Frequencies of hepatitis $\mathrm{B}$ and $\mathrm{C}$ infections among haemodialysis and peritoneal dialysis patients in Asia-Pacific countries: analysis of registry data. Nephrol Dial Transplant 2009; 245:1598-603.

12 Petrarulo F, Maggi P, Sacchetti A, Pallotta G, Dagostino F, Basile C. Infection occupational hazard at dialysis units and virus spread among relatives of dialyzed patients. Nephron. 1992; 613:302-3.

13 Urso S, Bonanno G, Lo Faro F, Fatuzzo P, Rapisarda F. Screening of relatives of anti-hepatitis- $C$ virus positive hemodialysed patients (preliminary data). Arch Gerontol Geriatr 1996; 22 Suppl 1:335-38. 